\title{
INVESTIGATING IN-SERVICE TEACHERS' PERCEPTIONS ON ONLINE AND AUTONOMOUS LEARNING
}

\author{
Masrizal $^{1}$, Ika Apriani Fata ${ }^{2 *}$, Nira Erdiana ${ }^{3}$
}

${ }^{1}$ Lecturer, Department of English Education, Faculty of Teacher Training and Education, Universitas Syiah Kuala, Banda Aceh, Indonesia; ${ }^{2 *}$ Lecturer, Department of English Education, Faculty of Teacher Training and Education, Universitas Syiah Kuala, Banda Aceh, Indonesia; ${ }^{3}$ Lecturer, Department of English Education, Faculty of Teacher Training and Education, Universitas Syiah Kuala, Banda Aceh, Indonesia.

Emails: ${ }^{1}$ masrizal@unsyiah.ac.id, ${ }^{2 *}$ ika.apriani@ unsyiah.ac.id, ${ }^{3}$ niraerdiana@unsyiah.ac.id Article History: Received on $23^{\text {rd }}$ March 2020, Revised on $28^{\text {th }}$ April 2020, Published on $24^{\text {th }}$ May 2020

\begin{abstract}
Purpose of the study: The aim of this study is to investigate in-service teachers' perception of online and autonomous learning and what types of obstacles they face during the program. It investigates the practice of autonomous learning classrooms by 101 Indonesian in-service English teachers in an entirely online learning environment, where skills and learning tools are incorporated to form integrated autonomous learning activities.
\end{abstract}

Methodology: This research was conducted at Universitas Syiah Kuala, Indonesia. Online questionnaire was used to gather information from 101 participants about their autonomous learning experience through task-based instructions (TBI).

Main Findings: Our research results indicated that the range of modules and tasks given to the in-service teacher participants were able to foster independent learning. Findings suggest that in-service teachers showed positive attitudes towards the implementation of online autonomous learning, while limited task instructions, technical issues, and communication constraints were among obstacles faced by the participants during the program.

Applications of this study: It is hoped that the findings of the present study will contribute to the development of the existing literature in the field of teacher training and can be used as an important input for the improvement of the current teacher training program.

Novelty/Originality of this study: This study is intended to draw conclusions from a series of actual research data and contribute a new angle to the existing research on teachers' perception on online and autonomous learning.

Keywords: Autonomous, In-service Teacher, Online Learning, Perception, Teacher Training.

\section{INTRODUCTION}

Technology and its powerful contribution to education has become a widespread phenomenon in the past few decades. As a result of significant growth in internet technology, particularly in the area of education, online courses are becoming increasingly popular among students and educational institutions. This, for a number of reasons, has influenced teachers' beliefs and experience toward teaching positions, including those in the Aceh province (Ningsih \& Fata, 2015). More and more teachers have been involved in a new type of teaching and learning experience, particularly those involving the use of technological devices and the internet. As a result, the way teachers and students view the internet and technology has also been rapidly changing, particularly when they become one of the recipients of such interactions. Technical problems and obstacles have also been recorded following this rapid transfer from the traditional way of learning to something that is much more technologically-based.

In the area of language learning, this enables learners to access more reliable authentic materials, practice using them in all integrated skill tasks, or even interact with native speakers at no time limit. A vast number of learning media are now available through different platforms ranging from those with general contents such as You-tube to those with fully academic settings such as Blackboard, Moodle, and Brightspace (Lee, 2016). Such an interaction, in which learners are given thoroughgoing access to authentic materials, is sometimes seen essential in a foreign language learning (Masrizal, 2014). In fact, most universities in the world have integrated such learning as part of their standard system that all students must have access to (Sergeeva, et al, 2019). This in turn is expected to improve learning experience and quality, including the way learning participants perceive such a new type of learning. The results are much improved learning productivity, flexible classroom settings, and classroom distribution at reduced costs (Blake, 2011).

A vast number of computer-assisted language learning (CALL) studies have revealed the advantages and disadvantages of online learning in language teaching. Its flexibility and accessibility are among those that have been rated the most (Lee, 2016). In addition, scholars have also included other advantages such as its ability to foster autonomous learning and enhance collaborations among participants of the course (Guth \& Helm, 2010; Yusnimar, 2019), for instance, suggested that learners showed positive reactions to online classroom and presented equal performance to the traditional classroom settings. It is merely due to the demands of technology and other factors, there is no denying that today, changes arise in communication's form or platforms compared to the previous years (Othman, et al., 2019). In some cases, where student's computer literacy was limited, CALL tends to come up with potential downsides. Moreover, the 
lack of face-to-face communication and teacher guidance might also lead to potential weaknesses of such a setting (Reinders \& Hubbard, 2013).

Online learning has rapidly become a new invention in classroom interaction since the last decades, especially when the internet technology started to become a widespread influence in human's modern life. Following this, online courses became one of the preferred choices in the way classroom interactions were chosen to be carried out (Silviyanti, 2014). In this regard, it has come to our agreement that online courses are able to offer some advantages both to administrators or instructor and learning participants in the form of convenience and self-directed learning, especially when compared to the traditional way of learning (Matsubara \&Yoshida, 2018). The system, however, is also widely known to have a number of possible downsides, which are parts of our focus to be investigated in the present study. In practice, learners and instructors rarely have face-to-face interactions unless it is a hybrid, which is referred to as a 'blended' program, where both parties are provided with a physical classroom in addition to their online course (Gilbert, 2001). In addition, many learners frequently have problems with self-management, making it hard for them to adapt with this new type of learning environment. For these reasons, it is necessary to construct a learning condition where students are able to take advantage from interactions and collaboration with other learners (Ediansyah, et al., 2019).

The present study was intentionally launched to investigate multidimensional factors that contribute to the success of a particular online and autonomous learning program. Our central aim was to expose how our research participants, who were also teacher participants of an online learning program they were involved in, perceived their experience of such learning interactions. In the present scope, respondents are in majority in-service teachers who come from different regions, most of which with difficult access to stable internet connections. Our findings are expected to light out language teachers on the use of online learning approach both for their professional training in the future and possible use for their daily teaching at their respective schools. Building on what has been discussed earlier, the current research intends to address the following research questions: 1). What are in-service teachers' perceptions on online autonomous learning? 2). What obstacles are faced by in-service teachers at the autonomous learning stage?

\section{LITERATURE REVIEW}

\section{Autonomous Learning and Computer-Assisted Language Learning}

In language learning, one of the key elements that have been part of a vast amount of discussion in the literature is learner autonomy, which is commonly defined as an ability to manage independent learning. In a much wider context, it is translated as learner's independence and capability to regulate his or her own learning both in on-line and off-line classrooms (Lee, 2016). However, it should not be translated that students fully self-regulate their own learning all of the time as an instructor is still needed to guide, monitor, and evaluate the learning process throughout the course (Little, $\underline{2007)}$.

In this area of research, studies have demonstrated transformation of old practices in language classrooms to a brandnew way of teaching languages through online interactions, either fully or in a 'blended' way (Hockly, 2015). In addition (White, 2006) merely highlighted 'the shifts from a concern with structural and organizational issues to focus on transactional issues associated with teaching/learning opportunities within emerging paradigms for distance language learning' (Hockly, 2015). The study emphasized the development of a growing body of research in the area of online learning since the early 1990 s, one of which was initiated by the Open University in the UK, to its widespread applications in the current years.

Studies have argued about the effectiveness of online learning, mainly focusing on how such a learning setting is necessarily 'better' than its traditional setting counterparts. In their meta-study, Means, et al. (2009) reported that, based on a review of 1,000 empirical studies, 'blended learning was the most effective in terms of improved learning outcomes'. This result, although not necessarily representing the application of a fully online learning setting, suggests that online learning offers promising effects in the area of education, particularly language learning. However, we also need to highlight that whether online learning is necessarily better than the traditional setting, or vice versa, is very much dependent on different factors such as funding and investment, students willingness to manage their own learning, technical back-up and training, infrastructure, and many others (Palloff \& Pratt, 2013; Zakrzewski \& Bull, 1998).

\section{Task-Based Instruction (TBI) and Technological Pedagogical Content Knowledge (TPACK)}

Recent technology in communication has advanced the way L2 teachers and learners interact in the teaching and learning process. One of the most advanced developments is called Task-Based Instruction (TBI), which claims that language learning will result from creating the appropriate kinds of interactions in the class (Sari, 2016). Through TBI, students use the target language to work on tasks that are related to actual contexts and use the available linguistic knowledge to share and exchange information. For this reason, it has been well suggested that TBI facilitates and promotes second language acquisition and teaching (Lee, 2016).

TBI has been implemented in a wide range of language teaching contexts, from teaching language learners to training experienced in-service teachers to improve their teaching capabilities. In practice, the latter commonly puts more emphasis on Technological Pedagogical Content Knowledge (TPACK), a model of which was originally developed by (Shulman, 1986). The current format includes 7 components: (1) technological knowledge (TK), (2) content knowledge 
(CK), (3) pedagogical knowledge (PK), (4) pedagogical content knowledge (PCK), (5) technological content knowledge (TCK), (6) technological pedagogical knowledge (TPK), and (7) technological pedagogical content knowledge (TPACK).

We may now be wondering what types of skills should be taught to in-service teachers through online courses. There is a growing number of debates in the literature regarding this matter. However, many have suggested that interpersonal communication skills should have a specific focus. Specifically, participants should be assisted with building communication repertoire and opportunities to implement skills, including chances to evaluate and modify behaviours. In one example, in-service teachers were provided with a video of a lesson and they were given a rating form to evaluate but were never asked to evaluate the teacher's understanding of theoretical construct (Capraro, et al., 2001). This gives us a general understanding that successful professional development program for teachers should accommodate teachers with the guidance to develop efficient classroom in order to reach the best output (Atkin, et al., 2001; Baleni, 2015; Putri, et al., 2019) based on national standard (Pryor \& Bitter, 2008).

\section{METHODOLOGY}

This study was initially designed to investigate teachers' perspectives on the use of online learning systems for their inservice training program. The program itself consists of two evidently distinguishable modes of learning, namely online and in-class workshops. The former is a three-month fully autonomous learning system where each participant is provided with an online account in order to gain full access to the learning platform. The latter is an entirely traditional classroom setting where the in-service teachers meet their instructors, all of whom are university lecturers, for more hands-on learning interactions. The present study focuses on the first mode, which is a fully online learning environment.

The online learning platform aims to develop both the English teachers' pedagogical and professional competencies, thus all the activities were designed to include materials and tasks in both domains (Johnston, 2004). Task-based activities were created for individual assignments and must be completed independently by all the participants in order to be qualified for the next stage. To support and optimize learning, an instructor was appointed for each module and was required to provide learning guidance and corrective feedback throughout the course. The teacher participants were expected to familiarize themselves with a fully flexible autonomous learning classroom through Task-Based Instructions. In addition to the online support through the platform, the participants also received relevant technical and material-related support through a group-chatting platform.

For the present study, 101 participants were purposely recruited to share their opinion about the program. Most of the informants were from the current year batch, but a small number of them were also recruited from the previous batch. They are coming from educational teachers' professions in Aceh. Aceh is one of the provinces in Indonesia that has specific benefits of shari'a law but follows the rules and terms of education from the government itself (Fata, et al., 2018; Habiburrahim, et al., 2020). There is no difference in the materials and learning settings of both years, so participants were asked questions and gave feedback about similar objects. All participants are non-native speakers of English and they had been teaching English for at least five years prior to enrolment to the program. In addition, all of them had completed their undergraduate major in English education, so we expect them to have sufficient linguistic proficiency for their current teaching job. With regards to computer knowledge and technology, most participants were competent in Web 2.0 technology, including social media. However, a small number of them had been exposed to such an online course before, thus many of them were due to be introduced to the online learning platform (henceforth called SPADA) used by the researchers' institution.

SPADA hybrid learning online platform is nationally used by over 50 training institutions in Indonesia as a learning medium for in-service teacher training programs. Currently, 65.237 in-service teachers are participating in the program and a small number of these participants are trained at Universitas Syiah Kuala Teacher Training Program, where this study took place.

The course was originally designed to fit learners needs, especially considering their time and distance constraints. By taking part in the course, they were able to perform learning from their own offices or residences, without having to leave their daily tasks of teaching. The class contained a collection of modules accompanied by assignments and formative and summative tasks or assessments. Course information (including course components, grading system, and resources) is already provided within each module and, when necessary, instructors provide additional information through scheduled posts. Regular announcements and messages are sent frequently both to the group and individually when deemed necessary. Through daily activities, participants were required to visit the learning site regularly (subject to minimum activity logs) to be actively involved in learning which includes reading the materials, watching videos, uploading tasks, participating in quizzes, and many others. All completed assignments and tasks were submitted through student's account or uploaded to an external platform (i.e. YouTube) whenever required.

All activities during the online course are conducted online and no physical meeting takes place between participants and instructors, as also suggested by Dixson and Worrell (2016). Based on the researcher's observations and informal interviews with instructors, most participants were able to complete the tasks independently regardless of skills. Most tasks were relatively straightforward and could be completed with basic web interface skills. When required to do tasks 
that require more advanced computer skills, such as producing videos or graphics, participants were allowed to seek for technical assistance from others, but need to assure that the produced task is the result of their own effort (Donelli$\underline{\text { Sallee, 2018). }}$

\section{RESULTS AND DISCUSSION}

In the present study, different instruments were used for the purpose of collecting data from the respondents. First of all, the online survey was designed to gather information about participants' perceptions regarding their online learning experience. The survey questions highlight details about participants' expectations prior to the course, their involvement, and specific views regarding particular modules, presentations, and technical or administrative facts. As mentioned previously, 101 respondents participated in the survey consisting of 30 statements and open-ended questions about the program. The 5-point Likert scale ranging from Strongly Disagree to Strongly Agree was used to gauge different opinions from the participants. In the present paper, only a collection of the statements will be included for our discussion. Others have been intentionally left for further publications.

In addition, a collection of task samples was gathered and supporting data to provide further insights into participants' practices in completing the program and its tasks. The researchers made every effort to assure that the samples collected were representative to those participated in the previous survey. For this purpose, instructors from different classes and modules were contacted so that access to participants' submitted tasks was granted. The researchers also requested special permission from training administrators in order to access particular data related to participants' submitted tasks. Data from this document are used to evaluate how seriously participants completed their tasks. Prior to the commencement of this study, the researchers were informed that identification documents were submitted by more than one participant for the same task. Therefore, an evaluation of such document samples was necessary to provide evidence to such a claim. In addition, it is also worth investigating whether participants' answers in the survey were reflected in their course practices.

To gather additional information about participants' interactions during the program, informal interviews were planned to be held with instructors. One form of interview was run to gather information from the instructor's perspectives about their participants' involvement in the program and how they reviewed participants' activity during the course. The other interview was done in the form of small group interviews with selected participants to gather further and more focused information regarding participants' viewpoints about the course. Unfortunately, due to different reasons, only instructors were interviewed informally. Inputs from the interview were used to verify participants' ratings in their questionnaire, thus no specific discussion will be provided with regard to the interview data.

\section{Participants' Views Regarding Autonomous Online Learning}

In order to evaluate participants' views regarding their autonomous learning experience, we asked them to rate the following general statements about the objectives of the program and module-related statements as shown in the following table:

Table 1: Survey statements for general perceptions

\begin{tabular}{ll}
\hline No & Statement \\
\hline 1. & The objectives of the online program are well-planned. \\
\hline 2. & The learning modules used online are organized and easy to follow. \\
\hline 3. & The task instruction for each module is clear. \\
\hline 4. & The contents of the learning module are thoroughly developed. \\
\hline
\end{tabular}

All the statements above refer particularly to respondents' impression on the online course and how they perceived the learning materials. The following graph provides a more detailed look at their opinion distribution across the rating scales.

With regard to the first question, participants seem to be convinced with the objectives of the online course. Even though these statements were originally intended to get their overall opinion about the program in general, we could specifically highlight that most of the participants showed relatively positive impressions on the program. To this far, the data show that the participants found the objectives of the program to be positively relevant both to institutional needs and their own interests.

Similarly, when asked to express their opinion about the learning modules they were using, we found that almost $80 \%$ of the participants believed that learning modules were well organized. However, the relevant response was not reflected in the next statement about module instruction. Even though 58\% of them agreed that the instruction was clear, 35\% of them expressed neutral response, suggesting that the instructions were neither clear nor confusing for them. Their opinion about website contents appear to be highly positive as exposed in the fourth bar, indicating that most of the respondents were likely satisfied with the modules. 


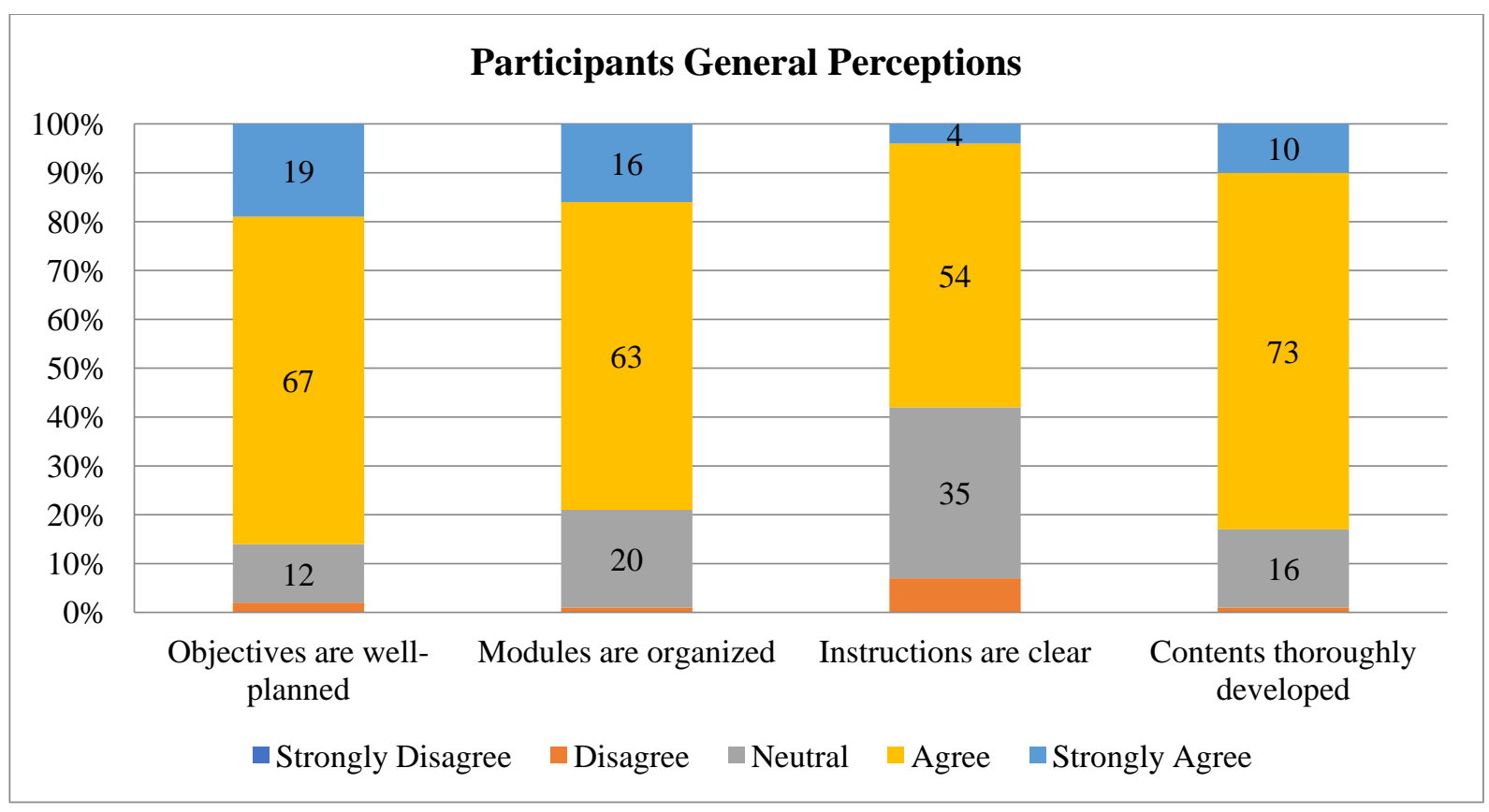

Figure 1: Participants' ratings for general perceptions

To a certain extent, the four statements only covered participants' perspectives about the course and its modules. Thus, this might only represent a one side judgement of the course in general. To provide a more detailed evaluation, we also asked the respondents to rate several statements in relation to the allocated time and facilities provided for the course, including their opinions about the practicality of the learning platform. The statements are summarized in the following table.

Table 2: Survey statements for general perceptions about course time and learning platform

\begin{tabular}{ll}
\hline No. & Statement \\
\hline 5. & The time allotted for the training is sufficient. \\
\hline 6. & The guideline book provided is adequate. \\
\hline 7. & The overall quality of the website is excellent. \\
\hline 8. & The contents provided on the website is adequate. \\
\hline
\end{tabular}

These statements were given to gather information that is relevant to particular technical (non-academic) factors that might affect participants' performance in the program. The overall ratings are characterized as in the following chart.

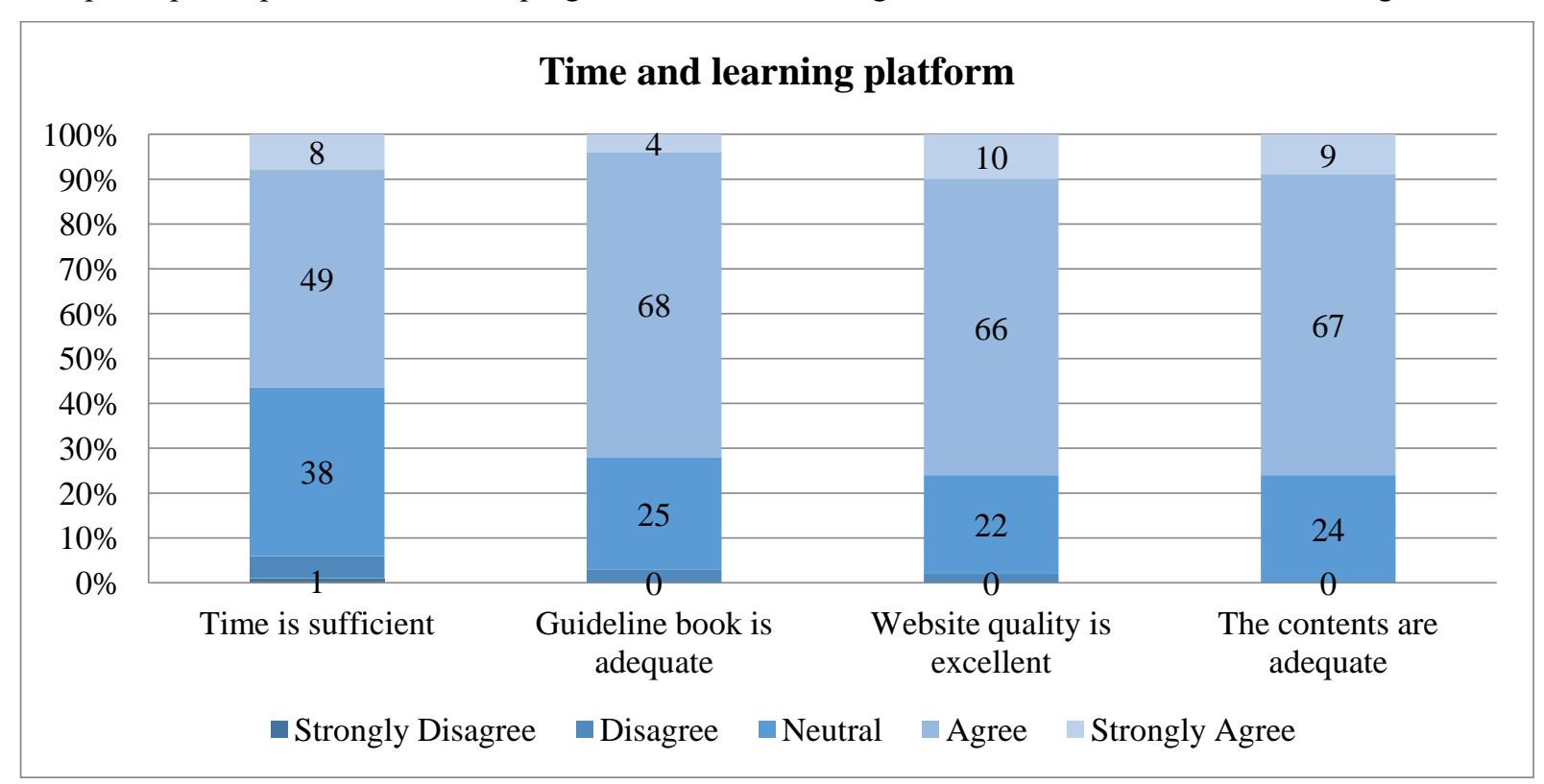

Figure 2: Participants' ratings for time and learning platform 
From this graph, we can see that a little over $50 \%$ of the respondents generally agree that time was adequate for them to go through the independent learning and tasks. However, a relatively large number who gave neutral responses might raise the question of whether many of them thought that they should have been given more time to complete the course. For this purpose, we reviewed additional data from respondents' comments. Consider the following extracts for further review:

E1: "Daring [online, trans] program is a good program to support the teachers to achieve the professional-grade without depending on the limited space. But it has a limited time for understanding the whole module at the same time. I think, for the time being, we should consider it."

E2: "Because I am a mother actually, I need additional time to complete all the tasks given."

From the two extracts, we can see that that who expressed disagreement with statement 5 admitted that time was not sufficient for them to complete the independent course. In the first extract, even though the respondent shows a positive attitude towards the program, it appears that (s) he had problems completing the tasks within the allocated time limit. Similarly, the second extract suggests the same idea, but rather with the emphasis on difficulties to manage time due to personal circumstances. This is not the case for all the respondents, but such data should be a good indication that further reviews will be necessary to improve the program.

As for statement 6,7 , and 8 , although over $70 \%$ of participants suggested that guideline, quality, and contents of the learning platform were acceptable to them, there were still approximately one fourth with no decision of whether they would agree or disagree with the statements. However, this can be seen as a strong indication that the overall quality of the program is within the required standard. Most respondents agreed that the guideline book and website quality were sufficient. Similarly, the module contents also seemed to be acceptable to most participants. This was not surprising as contents and the web platform were developed through a skilful collaboration of reliable teams at the Ministry of Higher Education and the provider of the learning platform.

The ratings given by the respondents with regard to their use of the learning platform must be supported by any evidence for possible obstacles they faced during the course. For this particular reason, we asked the respondents to rate relevant survey items with specific interests to this, as detailed in the following table.

Table 3: Survey statements for general perceptions about course time and learning platform

\begin{tabular}{ll}
\hline No. & Statement \\
\hline 9. & I faced obstacles during the course program. \\
\hline 10. & I faced obstacles when submitting the tasks online. \\
\hline
\end{tabular}

First of all, one might be wondering why these two statements were presented separately. It is perhaps worth mentioning that each item carries different messages to be understood by the respondents. Statement 9 represented all activities during which the participants conducted their independent study on any given module, while statement 10 was intended to capture their opinions about possible difficulties during tasks or assignments submission. Detailed for their response distributions are provided in the following graph.

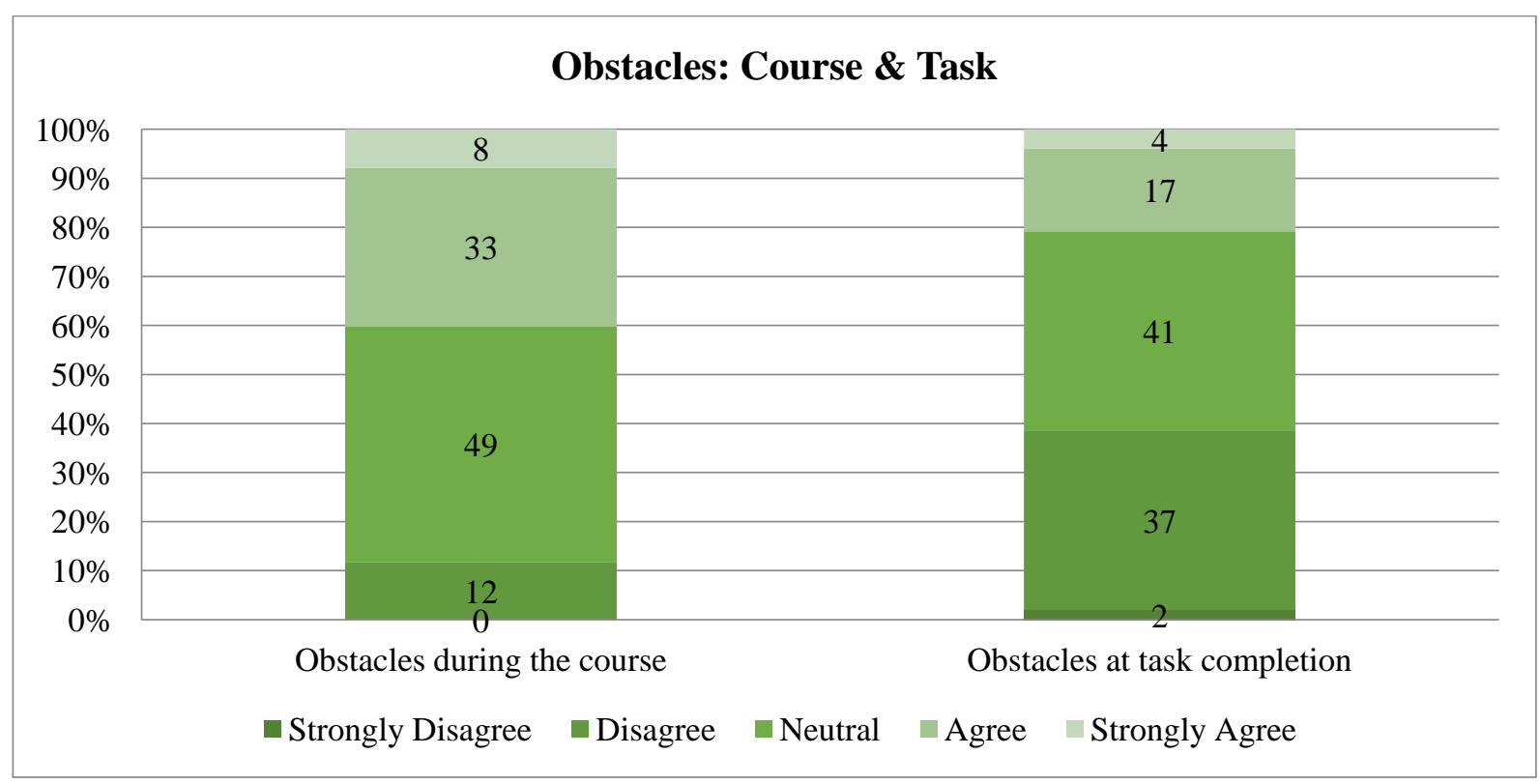

Figure 3: Participants' ratings for obstacles faced during the program 
The two bars reveal important information about the opposing degree of agreement and disagreement for obstacles faced during the course and at task submission. The first bar indicates that more participants admitted difficulties during the course, whereas in the second bar a small number of respondents expressed the same opinion for the task completion. Almost half of the respondents in both conditions were unable to rate whether they faced difficulties in both working on the course and completing the tasks. At this stage, data are only able to indicate that some participants faced difficulties during both stages of the course. As for the reasons for the types of difficulties they experienced, we have reviewed respondents' comments collected in the last section of the survey. In the following, we will review three of the most frequently occurring highlights in their comments.

\section{Task Instructions are Either Unclear or Unavailable}

Most of the comments from the respondents have raised the issue of clarity in the modules and tasks given. When asked to write their comments on what could be improved in the program, some of the responses we received are as follow:

E3: "There are some tasks that do not have clear instructions".

"The questions of the tasks contained in the module are sometimes difficult to understand".

From these extracts, it is obvious that participants faced a lot of obstacles during the course and when completing the tasks. In such autonomous learning contexts, learners must be given clear instructions on what they are supposed to do and how each assignment or task should be completed. Our data clearly suggest that there are noticeable problems to be handled by the administrators and instructors involved in the program.

\section{System/Connection Problems}

When evaluating respondents' comments, another noticeable obstacle they suggested was related to connection issues and system errors. Let us review the following extracts for further discussion:

E4: "It might be about a system problem because there are some teachers who have problems when doing online, this certainly hinders the online process".

"I think in the system of the PPG Daring Program. I think there are so many teachers that are confused about the system of progress".

The two extracts give us a detailed overview of the problems faced by the participants during the course. It is apparent that some of them encountered different technical issues along the way and this had triggered an extent of difficulties to them. We observed that those who rated 'agree' and 'strongly agree' to the statements 9 and 10 , including those who rated 'neutral', tend to give similar comments. Thus, we were wondering if such technical issues were widespread during the course of the program.

\section{Communication Constraints}

Further comments that we reviewed revealed that communication between the instructors and the participants was restricted. Most of the comments suggested an improvement in how the communication was taking place. The following two extracts highlight this.

\section{E5: "I think we need the communicative instructor when we are learning the module".}

"Fast response for our obstacles".

From these extracts, we learn that communication issues were obvious during the course. In the first extract, the respondent admitted that the instructor was not responsive at all. In the second, even though the instructor seemed to occasionally reply to messages, the response was not prompt enough to help those requiring immediate assistance. In both circumstances, immediate assistance must be prioritized as the delay could mean failure on a participant's side. It is also worth mentioning here that a response could come either from an instructor or technical staff (helpdesk).

Our overall results of this study support previous findings suggesting that online learning encourages, to some extent, interactions among learners and their instructors (Woodcock, et al. 2015). Our results also reveal that teachers are highly in favour of autonomous learning despite its complexities and all the technical difficulties faced during the program. The participants, however, criticized several downsides of the program, especially those related to the instructor's support and availability. This is particularly relevant to previous findings in the literature, especially those advocating a blended approach (Stevens, 2018). Poon (2013), for instance, suggested that online learning should be presented not only through an online platform, but also complemented by face-to-face learning where participants are able to have access to hand-on practices and material support previously introduced in online discussions.

Half-way through the study, we were curious about teachers' acceptance of this new model of teaching-learning interactions. The researchers were eager to know if the current shift to e-learning would create any burden to the teachers, especially when we relate to the fact that most of them live in technologically under-developed regions where internet connections and access to technology are scarcely available. Our findings suggest striking evidence showing that teachers are mostly positive about their learning experience. In particular, we found no comments pointing particularly at 
their restrictions with learning devices and internet connections despite living in remote areas. This is particularly in contrast to previous findings suggesting that many teachers were reluctant to participate in such a program (Woldab, 2014; Korthagen, 2010).

By now, we have reviewed significant evidence pertinent to in-service teachers' opinions regarding their autonomous learning and some obstacles they faced during the program. Overall, respondents expressed mainly positive attitudes towards their online learning experience. This is particularly important to foster deep and meaningful learning and communicating their understandings toward learning materials given (Pillay \& Reynold, 2014; Yasin \& Fata,2020). However, some respondents still expressed their sceptical views towards module instructions, time given to complete the tasks, technical errors, and a degree of communication constraints between them and the instructors. This finding suggests that there are still rooms for improvement for future programs.

\section{CONCLUSION}

Even though the use of online courses is still controversial to many, the findings of this study have presented important evidence to the present practice of teaching in such settings. Consistent with previous findings by Means, et al. (2009), our findings indicated that English teachers were mostly engaged in the learning process. Research data particularly suggest that participants were mostly pleased with their experience and partially satisfied with the learning interactions. In general, participants' perceptions are mostly positive towards the program. However, the overcoming issues addressed for such an online learning platform are still many and, in fact, there are still rooms for improvement especially with regard to technical matters, instructor's involvement, and prompt assistance to participants. For this matter, we suggest that the responsible institution take necessary steps for the improvement in similar programs in the future. For instance, instructors should be given earlier access to the tasks so that they can re-word the instructions for better understanding by the participants.

In addition, we have noted in our data that connection issues and some technical errors were parts of participants' daily experience. In such a program, such conditions are those that must be avoided in the first place as live interactions between participants and their instructors are also very minimal. The institution should consider this input seriously and take necessary steps for improvement. In particular, instructors should be made aware that communication with participants is the most vital part of such a learning condition, especially when technical helpdesk is in absence. Our observation suggests that this was not sufficiently available, prompting a high number of criticisms from the participants. Informal interviews with selected participants confirmed that this was one of the most obvious problems during the program. They suggested that prompt response was vital for them to assure clear understanding to the given tasks and how to approach them. Some instructors, however, believed that they had given their best support to the participants despite several known restrictions that apply to their roles, one of which is the fact that tasks and their relevant instructions had already been prepared and finalised by the national team before being transferred to them. Thus, we found an obvious mismatch on the way this program is run, especially on the authority and the operating procedure is given to each particular instructor. It is probably due to limited data that we currently hold, but further investigation is clearly required.

Our study has also demonstrated that learner autonomy can be fostered through the implementation of computermediated tasks and digital tools. For instance, this finding provided evidence that in-service teachers were able to complete a set of lengthy autonomous learning regardless of technical difficulties in the process. Task-Based Instruction allows in-service teachers to use L2 English actively in order to complete the tasks of different skills. Finally, it has come to our attention that such an interaction may not be able to guarantee the originality of the tasks submitted by the learning participants. In this regard, we suggest that the implementing institution incorporate plagiarism checking tools to assure that the submitted tasks are of learners' own works. This is particularly challenging especially when it comes to assessing learners' tasks given through an online learning platform (Yulia, et al., 2019; Ogange et al., 2018; Vonderwell, et al., 2007). Since we did not conduct in-depth research on such a case, we may not be able to offer further data on this matter. However, pursuing such information may be of special interest of future researchers in the area.

\section{LIMITATION AND STUDY FORWARD}

Although the findings of the present study have revealed important data on the practice of autonomous learning through Task-Based Instructions (TBI), more in-depth studies are still needed. In the current research, we notice that several limitations are present. First of all, the study mainly investigated learners' views regarding the course which included the use of particular modules (Pedagogy and Professional) and course platform, and this might not be representative for other online learning settings or platforms. Secondly, the study collected data from participants who were at different stages of their online learning, which might affect their opinions as their learning experience was also different.

Future researchers are suggested to look at different online settings for their focus. When possible, they should limit the scope of the study as this may significantly ease the process of data collection and analysis. In addition, we also recommend looking at different online classroom platforms as they may present different and more insightful findings. We suggest collecting data from learners who are at the same stage of learning so that their opinions represent the same contexts or circumstances. Future studies should also be directed to investigate not only complete online format learning, but also a combination of online and face-to-face formats. It would be fascinating to see how learners perform in such a 
condition where learning is structured in a full autonomous online setting, then followed by a standard classroom environment.

\section{ACKNOWLEDGEMENT}

This work would have been impossible to accomplish without funding and support from Universitas Syiah Kuala and the Indonesian Ministry of Higher Education and Research, grant number 522/UN11/SPK/PNBP/2019. We would also like to express further appreciation to the Universitas Syiah Kuala of Teacher Training Program (PPG) for all the access given to collect our data.

\section{AUTHORS CONTRIBUTION}

All authors have contributed equally to this research in parts of grant designing the research, searching the literature, collecting data, analysing data, taking and sum up the conclusion.

\section{REFERENCES}

1. Atkin, J. M., Black, P., \& Coffey, J. (2001). Classroom assessment and the national science education standards. National Academy Press.

2. Baleni, Z. G. (2015). Online formative assessment in higher education: Its pros and cons. Electronic Journal of e-Learning, 13, 228-236.

3. Blake, R. J. (2011). Current trends in online language learning. Annual Review of Applied Linguistics, 31, 1935. https://doi.org/10.1017/S026719051100002X

4. Capraro, R., Capraro, M., \& Lamb, C. (2001). Digital video: Watch me do what I say! Paper presented at the Fall Teacher Education Conference of the Consortium of State Organizations for Texas Teacher Education. Corpus Christi, TX.

5. Dixson, D. D., \& Worrell, F. C. (2016). Formative and summative assessment in the classroom. Theory into Practice, 55(2), 153-159. https://doi.org/10.1080/00405841.2016.1148989

6. Donelli-Sallee, E. (2018). Supporting online teaching effectiveness at scale: Achieving efficiency and effectiveness through peer review. Journal of Educators Online, 15(3), 1-17. https://doi.org/10.9743/jeo.2018.15.3.13

7. Ediansyah, E., Kurniawan, D. A., Salamah, \& Perdana, R. (2019). Investigation of problem based learning: Process of understanding the concepts and independence learning on research statistics subject. Humanities \& Social Science Reviews, 7(5), 01-11. https://doi.org/10.18510/hssr.2019.7159

8. Fata, I. A., Yusuf, Q. Y., Sari, L. N. (2018). Figuring the figures of speech in Acehnese traditional song lyrics. Humanities Diliman, 15(1), 30-56

9. Gilbert, S. (2001). How to be a successful online student. McGraw Hill.

10. Guth, S., \& Helm, F. (2010). Telecollaboration 2.0: Language, literacies, and intercultural (Vol. 1). Peter Lang. https://doi.org/10.3726/978-3-0351-0013-6

11. Habiburrahim, H., Rahmiati, Z., Muluk, S., Akmal, S., \& Aziz, Z. A. (2020). Language, identity, and ideology: Analysing discourse in Aceh sharia law implementation. Indonesian Journal of Applied Linguistics, 9(3), 735-748. https://doi.org/10.17509/ijal.v9i3.23210

12. Hockly, N. (2015). Developments in online language. ELT Journal, 69(3), 308-313. https://doi.org/10.1093/elt/ccv020

13. Johnston, T. C. (2004). Online homework assessments: Benefits and drawbacks to students. Academy of Educational Leadership Journal, 8(3), 29-40.

14. Korthagen, F. (2010). How teacher education can make a difference. Journal of Education for Teaching, 36, 407-423. https://doi.org/10.1080/02607476.2010.513854

15. Lee, L. (2016). Autonomous learning through task-based instruction in fully online language courses. Language Learning \& Technology, 20(2), 81-97.

16. Little, D. (2007). Language learner autonomy: Some fundamental considerations revisited. International Journal of Innovation in Language Learning and Teaching, 1(1), 14-29. https://doi.org/10.2167/illt040.0

17. Masrizal. (2014). The role of negotiation of meaning in L2 interactions: An analysis from the perspective of Long's interaction hypothesis. Studies in English Language and Education, 1(2), 96-105. https://doi.org/10.24815/siele.v1i2.1829

18. Matsubara, M., \& Yoshida, H. (2018). Fostering autonomous learners of vocabulary acquisition using content-based ICT methods. Humanities \& Social Science Reviews, 6(1), 36-43. https://doi.org/10.18510/hssr.2018.617

19. Means, B., Toyama, Y., Murphy, R., Bakia, M., \& Jones, K. (2009). Evaluation of evidence-based practices in online learning. US Department of Education.

20. Ningsih, S. R., \& Fata, I. A. (2015). Exploring teachers' beliefs and the teaching profession in Aceh. Studies in English and Education, 2(1), 61-67. https://doi.org/10.24815/siele.v2i1.2235

21. Ogange, B. O., Agak, J., Okelo, K. O., \& Kiprotich, P. (2018). Student perceptions of the effectiveness of formative assessment in an online learning environment. Open Praxis, 10(1), 29-39. https://doi.org/10.5944/openpraxis.10.1.705 
22. Othman, S. S., Nayan, L. M., Tiung, L. K., \& Hassan, F. (2019). Issues and challenges of future newspapers. Humanities \& Social Sciences Reviews, 7(5) 364-373. https://doi.org/10.18510/hssr.2019.7541

23. Palloff, R. M., \& Pratt, K. (2013). Lessons from the virtual classroom: The realities of online teaching ( $2^{\text {nd }}$ ed.). Jossey-Bass.

24. Pillay, S., \& Reynolds, J. (2014). The pains and gains of blended learning: Social constructivist perspectives. Education \& Training, 56, 254-270. https://doi.org/10.1108/ET-11-2012-0118

25. Poon, J. (2013). Blended learning: An institutional approach for enhancing students' learning. Journal of Online Learning and Teaching, 9(3), 260-271.

26. Pryor, C., \& Bitter, G. (2008). Using multimedia to teach in-service teachers: Impacts on learning, application, and retention. Computers in Human Behavior, 24, 2668-2681. https://doi.org/10.1016/j.chb.2008.03.007

27. Putri, Z., Yoestara, M., Aziz, Z. A., \& Yusuf, Y. Q. (2019). The correlation between professional development training and English teachers' competence. Journal of Physics: Conference Series, 1232(1), 1-5. https://doi.org/10.1088/1742-6596/1232/1/012037

28. Reinders, H., \& Hubbard, P. (2013). CALL and learner autonomy: Affordances and constraints. In M. Thomas, H. Reinders, \& M. Warschauer (Eds.), Contemporary computer-assisted language learning (pp. 359-375). Bloomsbury.

29. Sari, D. F. (2016). Authentic materials for learning English: A study of EFL students in Aceh. Studies in English Language and Education, 3(2), 147-157. https://doi.org/10.24815/siele.v3i2.4962

30. Sergeeva, M., Serebrennikova, A., Nikolaeva, M., Suslennikova, E., Bondarenko, N., \& Shumeyko, A. (2019). Development of university teacher's innovative culture. Humanities \& Social Sciences Reviews, 7(4), 20-25. https://doi.org/10.18510/hssr.2019.743

31. Shulman, L. (1986). Those who understand: Knowledge growth in teaching. Educational Researcher, 15(2), 4-14. https://doi.org/10.3102/0013189X015002004

32. Silviyanti, T. M. (2014). Looking into EFL students' perceptions in listening by using English movie videos on YouTube. Studies in English Language and Education, 1(1), 42-58. https://doi.org/10.24815/siele.v1i1.1119

33. Stevens, J. (2018). Finding the balance: Creating meaningful assignments without overwhelming instructional workload. Journal of Educators Online, 15(3), 1-12. https://doi.org/10.9743/jeo.2018.15.3.9

34. Vonderwell, S., Liang, X., \& Alderman, K. (2007). Asynchronous discussions and assessment in online learning. Journal of Research on Technology in Education, 39, 309-328. https://doi.org/10.1080/15391523.2007.10782485

35. White, C. (2006). Distance learning of foreign languages. Language Teaching, 39(4), $247-264$. https://doi.org/10.1017/S0261444806003727

36. Woldab, Z. (2014). E-learning technology in pre-service teachers training: Lessons for Ethiopia. Journal of Educational and Social Research, 4, 159-166. https://doi.org/10.5901/jesr.2014.v4n1p159

37. Woodcock, S., Sisco, A., \& Eady, M. (2015). The learning experience: Training teachers using online synchronous environments. Journal of Educational Research and Practice, 5(1), 21-34. https://doi.org/10.5590/JERAP.2015.05.1.02

38. Yasin,B.,\& Fata,I.A. (2020). Discovering Policy, attitude, and constraints on school based management. Humanities \& Social Sciences Reviews, 8 (3) 39-48. https://doi.org/10.18510/hssr.2020.835

39. Yulia, A., Husin, N. A., \& Anuar, F. I. (2019). Channelling assessments in English language learning via interactive online platforms. Studies in English Language and Education, 6(2), 228-238. https://doi.org/10.24815/siele.v6i2.14103

40. Yusnimar. (2019). Autonomous learning and teacher guidance: Towards the improvement of EFL students' prepared talk in speaking practice. Studies in English Language and Education, 6(2), 228-238. https://doi.org/10.24815/siele.v6i1.10080

41. Zakrzewski, S., \& Bull, J. (1998). The mass implementation and evaluation of computer-based assessments. Assessment \& Evaluation in Higher Education, 23(2), 141-152. https://doi.org/10.1080/0260293980230203 